\title{
Survival, Persistence, and Infection Efficiency of Verticillium dahliae Passed Through the Digestive System of Sheep
}

Emmanouil A. Markakis, Laboratory of Plant Pathology, Institute for Olive Tree and Subtropical Plants of Chania, Hellenic Agricultural Organization Demeter, Agrokipio 73100, Chania, Crete, Greece; Eleftherios K. Ligoxigakis, Laboratory of Plant Pathology, Plant Protection Institute of Iraklio, Hellenic Agricultural Organization Demeter, Iraklio 71003 Crete, Greece; Evangelia V. Avramidou, Laboratory of Forest Genetics and Tree Breeding, Faculty of Forestry and Natural Environment, Aristotle University of Thessaloniki, 54124, Thessaloniki, Greece; and Nikolaos Tzanidakis, Laboratory of Parasitology, Veterinary Research Institute, Hellenic Agricultural Organization Demeter, 57001 Thermi, Thessaloniki, Greece

\begin{abstract}
Markakis, E. A., Ligoxigakis, E. K., Avramidou, E. V., and Tzanidakis, N. 2014. Survival, persistence, and infection efficiency of Verticillium dahliae passed through the digestive system of sheep. Plant Dis. 98:1235-1240.

The present study was carried out to determine the survival, persistence, and infection efficiency of Verticillium dahliae passed through the digestive tract of sheep. Eggplant, turnip, tomato, and pepper plants were artificially inoculated with $32 \mathrm{~V}$. dahliae isolates. At 33 days postinoculation, the disease incidence and severity for eggplant, turnip, tomato, and pepper plants were 99.6, 96.2, 62.9, and 18.0\% and 80.1, $49.8,19.8$, and $7.8 \%$, respectively. The infected plant material was used to feed four 1-year-old sheep. Polymerase chain reaction assays revealed the presence of $V$. dahliae DNA in fecal samples received from animals' rectum on days 1,2,3,4, and 5, whereas the pathogen DNA was not detected on 0,6 , and 7 days after feeding. Pathogenicity

tests were conducted by transplanting eggplant plants into soil substrate amended with $20 \%$ decomposed manure, collected from the four animals fed with the infested forage. At 52 days after transplanting, manure-treated plants exhibited Verticillium wilt symptoms whereas, 2 months later, disease incidence, disease severity, and percentage of positive $V$. dahliae isolations from stem tissues were 58.3, 30.7, and $48.3 \%$, respectively. Symptoms or positive isolations were not observed in control plants (transplanted in 100\% soil substrate). This is the first report of the active role of $V$. dahliae passed through the digestive system of sheep as effective inoculum for host plants, in relation to the span persistence and transmission via the sheep carrier.
\end{abstract}

Verticillium wilt is a vascular wilt disease of a wide range of plants caused by three species of the Verticillium genus: Verticillium dahliae, V. albo-atrum, and V. longisporum (13). V. albo-atrum and $V$. dahliae are the two most common species, causing devastating losses to more than 350 agriculturally important plants. Important crops at risk include cotton, tomato, hops, alfalfa, potato, and olive (22). V. albo-atrum has a limited host range; it survives in the soil and on diseased plant remnants as dark resting mycelia but it cannot persist in soil for more than 2 years in the absence of a susceptible host plant. $V$. dahliae invades a wide range of plants, including vegetables, fruit, ornamentals, oilseed crops, fiber crops, woody perennials, and weeds $(16-18,22,24)$, and survives in the soil as microsclerotia for more than 20 years (28). Although $V$. dahliae invades various plants, isolates can vary in terms of host range $(2,7,8,15,23,26)$, virulence $(1,4-6,20,21,26,27)$, and microsclerotium formation (25). Furthermore, microsclerotia among isolates can differ in lethal temperature tolerance (14).

Once introduced into an area, the pathogens can be disseminated by several means. Direct root contacts can transmit the pathogen from diseased to healthy plants (9). Farm machinery and even workers' boots can spread V. albo-atrum within and between alfalfa fields (9). A number of insects, including potato leaf hopper, leaf cutter bees, and aphids, have been reported to transmit conidia of Verticillium and, because these insects can cause lesions to the plant that serve as an entry for the Verticillium spp., they can help in transmitting the disease (22). In addition, V. albo-atrum has been shown to remain viable in insect feces and capable of infecting

Corresponding author: E. A. Markakis, E-mail: markmanos1979@yahoo.gr Accepted for publication 17 March 2014.

http://dx.doi.org/10.1094/PDIS-12-13-1201-RE

(C) 2014 The American Phytopathological Society alfalfa plants that grow near the infested feces (10). Bees can carry conidia of $V$. albo-atrum on their bodies directly or they can carry pollen grains infected with the pathogen (12). V. albo-atrum can survive passage through the digestive tract of sheep, and infected alfalfa stems in manure piles were shown to harbor viable $V$. alboatrum 6 weeks after burying (11). However, the fungus did not persist in the digestive tract and was absent in feces collected two or more days after the animals were returned to a diet free of the pathogen. V. dahliae has also been reported to survive the digestive process in sheep fed on infested stubble, and viable microsclerotia were recovered from the manure pile 2 years later (19).

Even though both $V$. albo-atrum (11) and $V$. dahliae (19) can survive passage through the digestive tract of sheep, infection efficiency of manure and inoculum persistence span in an animal body has not been determined. In Crete (southern Greece), where Verticillium wilt incidence in fields has dramatically increased in the last decades (15-18), agriculture and sheep farming occupy a high percentage of the population in rural areas. Sheep flocks are often moved to different pastures during the grazing season and fed on the harvested or abandoned fields. Moreover, manure is commonly used as a soil amendment to increase organic matter content of soil in greenhouse and open-field crops. Considering that $V$. dahliae is widely distributed throughout Crete (15-18), invades and survives in a wide range of cultivated plants and weeds $(17,18,22,24)$, and can be dispersed by manure from sheep fed on infested stubble (19), knowledge of this carrier effectiveness in pathogen transmission is important for risk assessment and disease management. Grazing on V. dahlia-infested stubble may contribute to $V$. dahliae dispersion in pathogen-free areas and to the increase of Verticillium wilt incidence in fields.

In view of all the above, the main objectives of this study were to (i) develop an efficient, reliable assay to test infectivity of $V$. dahliae from sheep feces; (ii) corroborate whether $V$. dahliae survives passage through the digestive tract of sheep; (iii) determine the infection efficiency of the manure coming from animals fed with infested forage; and (iv) investigate the inoculum persistence 
span of $V$. dahliae in an animal body after the consumption of Verticillium spp.-infected plant material.

\section{Materials and Methods}

Plant material. Plant material consisted of eggplant ('Black Beauty'), turnip ('Snow Ball'), tomato ('Belladonna'), and pepper ('California Wonder') plants.

$\boldsymbol{V}$. dahliae isolates. The 32 isolates of $V$. dahliae used in this study for infested forage preparation were collected from cultivated and self-sown hosts showing wilt symptoms and belonging to 19 plant species in eight different botanical families between 1988 and 2009 in Crete.

Infested forage preparation. Seedlings of eggplant, turnip, tomato, and pepper plants were grown in plastic pots ( 4 by 4 by 4 $\mathrm{cm}$ ) containing soil substrate (Potground; Klasmann). They were removed from the substrate at the second-true-leaf stage and washed with tap water; then, their roots were trimmed to $3 \mathrm{~cm}$ and dipped in a conidial suspension for $20 \mathrm{~min}$. Inoculation experiments were conducted by root dipping eight plants of each plant species in each $V$. dahliae isolate conidial suspension. Conidia were produced by growing each isolate of $V$. dahliae in potatodextrose broth at $160 \mathrm{rpm}$ and $21 \pm 0.5^{\circ} \mathrm{C}$ for 7 days; conidia were harvested by filtration through three layers of cheesecloth and the suspension was centrifuged at $3,000 \times \mathrm{g}$ for $10 \mathrm{~min}$. Spores were resuspended in distilled water and their concentration was adjusted to $5 \times 10^{6} \mathrm{ml}^{-1}$. Control plants were mock inoculated by root dipping in sterile distilled water. After inoculation, seedlings were repotted in individual 9-by-9-by-10-cm plastic pots containing sterile soil and kept in a greenhouse at $22 \pm 5^{\circ} \mathrm{C}$ with a 12-h photoperiod for 33 days. To verify the presence of $V$. dahliae in plants vessels, petiole sections of diseased plants were surface-disinfected by $\mathrm{NaClO}(0.5 \%$ commercial bleach) for $2 \mathrm{~min}$, rinsed with sterile distilled water, and placed onto acidified potato-dextrose agar (PDA), and plates were incubated at $22^{\circ} \mathrm{C}$ in the dark for 14 days.

Sheep feeding: $\boldsymbol{V}$. dahliae passage bioassay. At 33 days post artificial inoculation with $32 \mathrm{~V}$. dahliae isolates, eggplant, turnip, tomato, and pepper plants were cut above the soil level (whole plant material; about $11.2 \mathrm{~kg}$ fresh weight). For the purposes of the experiment, four female 1-year-old healthy animals (A, B, C, and D) of the local "Sfakia" sheep breed were fed with the collected plant material on day 0. Animals were kept in a separate sheltered place of the barn, bounded by metal mesh. Four randomly selected healthy sheep of the same flock, not fed with infested debris, served as the control. Control sheep and treated animals prior to day 0 and after day 7 were fed with a pathogen-free ration (corn, soybean meal, sunflower meal, wheat meal, barley, and a vitamin and mineral supplement) plus alfalfa hay. Fecal samples were collected directly from animals' rectums daily for 1 week and stored at $-80^{\circ} \mathrm{C}$. On day 7 , the manure accumulated on cement ground of the animal enclosure was collected. The manure was piled on a plastic film, watered, and turned regularly during the next 3 months until decomposing, followed by a 2-month curing period. Turnings were performed and water was added at the end of each thermophilic phase. Manure was used in pathogenicity tests straight after the end of the curing period.

Pathogenicity tests with infested manure. Eggplant was the most susceptible host against all $V$. dahliae isolates tested in pathogenicity assays for infested forage preparation (Table 1). Therefore, pathogenicity tests with infested manure were conducted by transplanting eggplant plants (Black Beauty) at the two-true-leaf stage in 2-liter-capacity pots containing soil substrate (Potground; Klasmann) amended with $20 \%$ decomposed manure. Plants were kept in greenhouse at $22 \pm 5^{\circ} \mathrm{C}$ with a 12 -h photoperiod. Control plants were transplanted in pots containing pure soil substrate (Potground; Klasmann). Pathogenicity tests were evaluated by estimating disease incidence and severity. Furthermore, vascular colonization by actively growing $V$. dahliae was determined in each of the sampled eggplant plants by isolating the fungus onto acidified PDA. Three inoculation experiments with eight plants in each experiment were conducted.
Disease assessment. Verticillium wilt symptoms on eggplant, turnip, tomato, and pepper plants used for infested forage preparation were recorded at 33 days after root dipping inoculation. Regarding the plants employed for the determination of the infection efficiency of manure, symptoms were observed periodically and recorded at 112 days after transplanting the eggplant plants into a soil substrate-decomposed manure mixture. In both cases, disease severity was calculated from the number of leaves that showed wilting as a percentage of the total number of leaves of each plant, whereas disease incidence was estimated as the percentage of infected plants.

Pathogen isolation. To verify the presence of $V$. dahliae in vascular tissues, all manure-treated and control eggplant plants were cut above the soil level, the leaves were removed, and stems were surface-disinfected throughout by $95 \%$ ethyl alcohol for $2 \mathrm{~min}$. For each plant, 10 xylem chips from the stem were placed onto acidified PDA after the removal of the phloem. Plates were incubated at $22^{\circ} \mathrm{C}$ in the dark for 14 days. The emerging fungus that grew out of tissue excisions was examined under a light microscope and identified as $V$. dahliae according to its morphological characteristics (22). Pathogen isolation ratio was expressed as percentage of positive $V$. dahliae isolation of each plant.

DNA extraction and polymerase chain reaction amplification. To detect the pathogen, DNA extraction from fecal samples (QIAamp Stool Mini Kit; Qiagen) and polymerase chain reaction (PCR) amplification (KAPA Taq PCR Kit; KapaBiosystems) using the specific primers internal transcribed spacer (ITS)1-F and ITS2$\mathrm{R}$ (20) were performed, yielding a 347-bp amplicon, corresponding to $V$. dahliae. All PCR assays were carried out with an MJ Research PTC-200 Gradient. PCR performance included denaturation at $95^{\circ} \mathrm{C}$ for $3 \mathrm{~min}$; followed by 35 cycles of $1 \mathrm{~min}$ of denaturation at $94^{\circ} \mathrm{C}, 1 \mathrm{~min}$ of annealing at $60^{\circ} \mathrm{C}$, and $1 \mathrm{~min}$ of extension at $72^{\circ} \mathrm{C}$; and a final extension step at $72^{\circ} \mathrm{C}$ for $5 \mathrm{~min}$. Amplification products were resolved on agarose gel electrophoresis (1\% agarose in $1 \times$ Tris-acetate-EDTA buffer), stained with ethidium bromide, and visualized under UV light. Reactions were repeated three times and always included negative controls (no DNA) and positive controls (template DNA isolated from mycelium of the $V$. dahliae isolate 999-1, grown in pure culture).

Statistics. Data on disease incidence and disease severity on eggplant, turnip, tomato, and pepper plants in the infested forage preparation experiment were transformed with the $\arcsin (\mathrm{x})$ transformation before analysis of variance was applied. When a significant $(P \leq 0.05) F$ test was obtained for treatments, data were subjected to means separation by Tukey's honestly significant difference test $(P \leq 0.05)$. Data on disease incidence, disease severity, and positive $V$. dahliae isolations in manure-treated eggplant plants were also transformed with the $\arcsin (\mathrm{x})$ transformation and analyzed by carrying out a two-sample $t$ test $(P \leq 0.05)$.

\section{Results}

Virulence and pathogenicity of $V$. dahliae isolates on four plant species. Different hosts produced typical Verticillium wilt symptoms, including leaf flaccidity, chlorosis, yellowing, desiccation, defoliation, stunting, vascular discoloration, and occasionally plant death. Eggplant was the most susceptible host, followed by turnip and tomato, whereas pepper was less susceptible to the $V$. dahliae isolates tested (Table 1). The average disease severity and disease incidence values of Verticillium wilt caused by 32 isolates of $V$. dahliae on eggplant, turnip, tomato, and pepper plants were 80.0, 49.2, 20.0, and 7.4\% and 99.6, 96.3, 62.9, and $18.0 \%$, respectively, 33 days postinoculation (dpi).

In addition, disease incidence and disease severity values were 87.5 to 100.0 and 34.0 to $100 \%$, respectively, on eggplant and pathogenicity of isolates varied from highly to mildly virulent (Table 1). All isolates were pathogenic on turnip and disease incidence and disease severity values were 62.5 to 100.0 and 26.9 to $89.6 \%$, respectively. The pathogenicity of isolates on tomato and pepper plants varied from highly virulent to nonpathogenic. Therefore, 26 of 32 (about $81.3 \%$ ) and 6 of 32 (about 18.8\%) isolates were path- 
ogenic on tomato and pepper, respectively. However, the virulence of $V$. dahliae isolates was not consistent on all hosts. Therefore, isolates characterized as highly virulent on a specific plant species were mildly virulent or avirulent on other species tested (for example, isolate 31-1).

Detection of $V$. dahliae DNA passed through the digestive system of sheep. $V$. dahliae DNA was present in the feces of sheep $\mathrm{A}, \mathrm{C}$, and D on day 1 but detected in the feces of sheep B no sooner than day 3 (Fig. 1). Half of the fecal samples were found positive on days 2 (sheep $\mathrm{C}$ and $\mathrm{D}$ ) and 3 (sheep $\mathrm{B}$ and D), whereas $V$. dahliae DNA was present in only one fecal sample (sheep D) on day 5 (Fig. 1). However, V. dahliae DNA was not detected in the feces of any sheep on days 0,6 , and 7 , which suggests no further dissemination of the pathogen. Interestingly enough, fungus DNA in sheep D was not identified in any of the triplicates tested for day 4. V. dahliae DNA was not detected in any of the fecal samples selected from the four control animals.

Infectivity of manure. Verticillium wilt symptoms were first exhibited on manure-treated plants 52 days after transplanting eggplant plants in the soil substrate-decomposed manure mixture. Sixty days later, disease incidence and severity were 58.3 and $30.7 \%$, respectively. At the same time, vascular colonization by actively growing $V$. dahliae was verified and the percentage of positive $V$. dahliae isolations onto acidified PDA for manure treated plants was $48.3 \%$. Neither symptoms nor positive isolations were observed in control plants (Table 2).

\section{Discussion}

Phytopathogenic species of Verticillium invade the vascular tissues in roots and stems and cause vascular wilt in a large number of economically and agriculturally important plants. Thus far, nearly 80 plant genera, including more than 410 plant species, have been reported as susceptible to Verticillium wilt worldwide (22). Among species, $V$. dahliae and $V$. albo-atrum are the predominant plant pathogens worldwide.

Although $V$. albo-atrum has been extensively investigated on the basis of its ability to be transmitted by several insect and animal vectors $(10,12,22)$, studies regarding $V$. dahliae dissemination by animal transmitters are scarce (19).

Lopez-Escudero and Blanco-Lopez (19) reported $V$. dahliae transmission by infested manure. In particular, manure from sheep fed on infested stubble was used to establish an olive plantation and the remaining manure was left in a pile in the field. Two years after planting, many olive plants in the field showed Verticillium

Table 1. Isolates of Verticillium dahliae used in pathogenicity assays for infested forage preparation, along with their host and geographic origin

\begin{tabular}{|c|c|c|c|c|c|c|c|c|c|c|c|}
\hline \multirow[b]{3}{*}{ Isolate } & \multirow[b]{3}{*}{ Host $^{w}$} & \multirow[b]{3}{*}{ Location $^{x}$} & \multirow[b]{3}{*}{ Year $^{y}$} & \multicolumn{8}{|c|}{ Pathogenicity ${ }^{\mathrm{t}}$} \\
\hline & & & & \multicolumn{4}{|c|}{ Disease incidence $(\%)^{\mathrm{u}}$} & \multicolumn{4}{|c|}{ Disease severity $(\%)^{\mathrm{v}}$} \\
\hline & & & & Eggplant & Turnip & Tomato & Pepper & Eggplant & Turnip & Tomato & Pepper \\
\hline $410-2$ & Cauliflower & Lasithi plateau & 1997 & 100.0 & 100.0 & 100.0 & 0.0 & 93.3 & 49.2 & 33.1 & 0.0 \\
\hline $446-1$ & Cabbage & Lasithi plateau & 1997 & 100.0 & 100.0 & 25.0 & 0.0 & 85.3 & 64.4 & 4.3 & 0.0 \\
\hline $448-2$ & Broccoli & Lasithi plateau & 1997 & 100.0 & 100.0 & 0.0 & 0.0 & 42.4 & 30.8 & 0.0 & 0.0 \\
\hline $487-1$ & Anthemis & Lasithi plateau & 1997 & 100.0 & 100.0 & 60.0 & 0.0 & 84.1 & 43.3 & 18.6 & 0.0 \\
\hline $520-1$ & Romaine lettuce & Lasithi plateau & 1997 & 100.0 & 100.0 & 87.5 & 0.0 & 90.8 & 61.5 & 27.2 & 0.0 \\
\hline $439-6$ & Endive & Lasithi plateau & 1997 & 100.0 & 100.0 & 0.0 & 0.0 & 90.6 & 30.4 & 0.0 & 0.0 \\
\hline $555-1$ & Chicory & Lasithi plateau & 1997 & 100.0 & 100.0 & 37.6 & 0.0 & 97.9 & 42.5 & 5.0 & 0.0 \\
\hline $354-1$ & Summer squash & Lasithi plateau & 1997 & 87.5 & 80.0 & 75.0 & 0.0 & 85.6 & 41.7 & 12.1 & 0.0 \\
\hline $473-1$ & Summer squash & Lasithi plateau & 1997 & 100.0 & 100.0 & 100.0 & 0.0 & 85.6 & 89.6 & 40.4 & 0.0 \\
\hline $179-4$ & Melon & Messara valley & 1988 & 100.0 & 100.0 & 100.0 & 0.0 & 79.6 & 54.4 & 24.5 & 0.0 \\
\hline $31-1$ & Cucumber & Messara valley & 1999 & 100.0 & 87.5 & 87.5 & 0.0 & 100.0 & 85.0 & 21.7 & 0.0 \\
\hline $\mathrm{xxx}-1$ & Wild sweet pea & Lasithi plateau & 1997 & 100.0 & 100.0 & 0.0 & 0.0 & 83.1 & 31.3 & 0.0 & 0.0 \\
\hline $453-1 \mathrm{a}$ & Wild sweet pea & Lasithi plateau & 1997 & 100.0 & 100.0 & 0.0 & 0.0 & 89.8 & 51.1 & 0.0 & 0.0 \\
\hline $453-1$ & Vetch & Lasithi plateau & 1997 & 100.0 & 100.0 & 0.0 & 0.0 & 78.5 & 29.7 & 0.0 & 0.0 \\
\hline $123-3$ & Olive & Iraklio & 1988 & 100.0 & 87.5 & 100.0 & 100.0 & 79.4 & 48.6 & 39.7 & 26.7 \\
\hline $802-1$ & Olive & Iraklio & 2000 & 100.0 & 100.0 & 75.0 & 0.0 & 84.8 & 63.3 & 14.3 & 0.0 \\
\hline 1100 & Olive & Messara valley & 2009 & 100.0 & 100.0 & 75.0 & 0.0 & 87.1 & 54.2 & 12.5 & 0.0 \\
\hline $98-1$ & Tomato & Chania valley & 1988 & 100.0 & 87.5 & 25.0 & 0.0 & 34.0 & 28.6 & 3.9 & 0.0 \\
\hline $136-1$ & Tomato & Messara valley & 1988 & 100.0 & 100.0 & 100.0 & 0.0 & 71.0 & 62.0 & 34.3 & 0.0 \\
\hline $150-5$ & Tomato & Messara valley & 1988 & 100.0 & 87.5 & 100.0 & 100.0 & 94.8 & 39.4 & 39.2 & 51.7 \\
\hline $164-1$ & Tomato & Messara valley & 1988 & 100.0 & 100.0 & 100.0 & 0.0 & 64.6 & 50.4 & 32.7 & 0.0 \\
\hline $171-2$ & Tomato & Rethimnon valley & 1988 & 100.0 & 87.5 & 100.0 & 100.0 & 96.9 & 42.6 & 31.3 & 40.8 \\
\hline $17-1$ & Eggplant & Chania valley & 1988 & 100.0 & 100.0 & 100.0 & 100.0 & 88.8 & 50.2 & 37.6 & 48.6 \\
\hline $113-1$ & Eggplant & Rethimnon valley & 1988 & 100.0 & 100.0 & 100.0 & 0.0 & 77.1 & 63.2 & 37.5 & 0.0 \\
\hline 998-1 & Eggplant & Messara valley & 2000 & 100.0 & 100.0 & 87.5 & 0.0 & 93.1 & 36.7 & 39.9 & 0.0 \\
\hline $999-1$ & Eggplant & Lasithi plateau & 2000 & 100.0 & 100.0 & 100.0 & 100.0 & 97.5 & 34.6 & 35.0 & 46.7 \\
\hline $273-1$ & Black nightshade & Lasithi plateau & 1992 & 100.0 & 100.0 & 37.5 & 0.0 & 77.4 & 57.9 & 10.2 & 0.0 \\
\hline $466-1$ & Black nightshade & Lasithi plateau & 1997 & 100.0 & 100.0 & 60.0 & 0.0 & 76.7 & 34.6 & 9.5 & 0.0 \\
\hline $43-4$ & Black nightshade & Chania valley & 1988 & 100.0 & 100.0 & 75.0 & 0.0 & 52.0 & 52.0 & 28.3 & 0.0 \\
\hline $459-1$ & Pepper & Lasithi plateau & 1997 & 100.0 & 100.0 & 0.0 & 75.0 & 52.3 & 51.7 & 0.0 & 22.1 \\
\hline $444-1$ & Potato & Lasithi plateau & 1997 & 100.0 & 62.5 & 37.5 & 0.0 & 52.5 & 26.9 & 4.9 & 0.0 \\
\hline $116-1$ & Okra & Rethimnon valley & 1995 & 100.0 & 100.0 & 66.7 & 0.0 & 93.8 & 72.9 & 41.7 & 0.0 \\
\hline Mean $^{\mathrm{z}}$ & $\cdots$ & $\cdots$ & $\cdots$ & $\begin{array}{r}99.6 \pm \\
0.4 \mathrm{a}\end{array}$ & $\begin{array}{r}96.3 \pm \\
1.5 \mathrm{a}\end{array}$ & $\begin{array}{r}62.9 \pm \\
6.8 \mathrm{~b}\end{array}$ & $\begin{array}{r}18.0 \pm \\
6.8 \mathrm{c}\end{array}$ & $\begin{array}{r}80.0 \pm \\
1.0 \mathrm{a}\end{array}$ & $\begin{array}{r}49.2 \pm \\
1.3 \mathrm{~b}\end{array}$ & $\begin{array}{r}20.0 \pm \\
1.4 \mathrm{c}\end{array}$ & $\begin{array}{l}7.4 \pm \\
1.1 \mathrm{~d}\end{array}$ \\
\hline
\end{tabular}

\footnotetext{
' Pathogenicity of isolates on eggplant ('Black Beauty'), turnip ('Snow Ball'), tomato ('Belladonna'), and pepper ('California Wonder') conducted by root dipping plants at the two-true-leaf stage in a suspension of $5 \times 10^{6}$ conidia $\mathrm{ml}^{-1}$ for each isolate or dipping into sterile distilled water for the control, prior to transplanting. Plants were further maintained in greenhouse at $22 \pm 5^{\circ} \mathrm{C}$ with a 12 -h photoperiod for another 33 days.

${ }^{u}$ Mean disease incidence of eight plants was estimated as the percentage of infected plants by each isolate, 33 days post artificial inoculation. Arcsin transformation was performed prior to statistical analysis.

${ }^{v}$ Mean disease severity of eight plants caused by each isolate was calculated from the number of leaves that showed wilting as a percentage of the total number of leaves of each plant, 33 days post artificial inoculation. Arcsin transformation was performed prior to statistical analysis.

w Originating host.

${ }^{x}$ Geographical location.

y Year isolated.

${ }^{\mathrm{z}}$ Mean \pm standard deviation. Within rows, values with different letters differ significantly according to Tukey honestly significant difference test $(P \leq 0.05)$.
} 
wilt symptoms. Then, the mean inoculum densities in piled manure and soil were 8.4 and 7.2 microsclerotia/g, respectively. The nearby inoculum densities found in both samples may suggest that some inoculum was already present in the soil before the application of manure, and that inoculum might have infected the olive plants. Therefore, a dual question has arisen: (i) whether inoculum survives passage through the digestive tract of sheep is still capable of infecting new hosts, although it undergoes mechanical, microbial, thermal, and enzymatic activities during the digestive process (3); and (ii) how long sheep carriers can disperse the inoculum.

Although $V$. dahliae invades various plants, the host range differs among isolates $(2,7,8,15,23,26)$. Moreover, isolates of $V$. dahl- iae vary in virulence on different herbaceous and woody hosts $(1,4-6,20,21,26,27)$ as well as in their ability to form microsclerotia in senescing plant tissues (25). Furthermore, microsclerotia of different isolates exhibit varying tolerance against temperature (14). It is also assumed that microsclerotia are the $V$. dahliae structures that can potentially survive passage through animals' digestive systems (19). Therefore, several isolates were employed in this study for inoculating three of the most common plant species (eggplant, tomato, and pepper) cultivated in commercial greenhouse and open-field systems in Crete, as well as one host (turnip) with proven susceptibility against all V. dahliae isolates used (15). Thus, it was ensured that an efficient number of microsclerotia would be

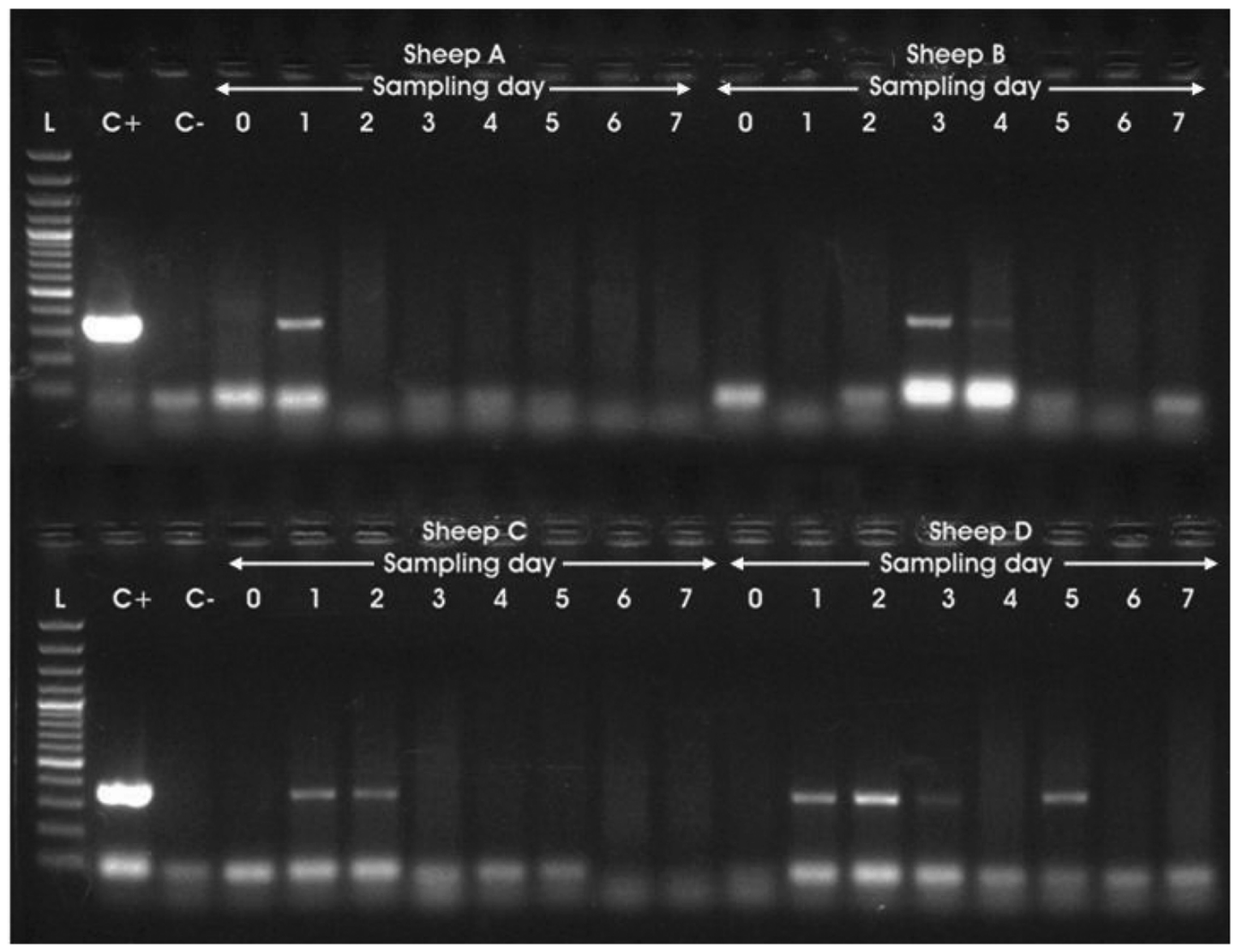

Fig. 1. Detection of Verticillium dahliae in samples of total DNA extracted from feces of four sheep ( $A, B, C$, and D). Fecal samples were collected from animals' rectums at 0 , $1,2,3,4,5,6$, and 7 days after feeding them with $V$. dahliae infested forage. Polymerase chain reaction assays were performed using $200 \mathrm{ng}$ of total DNA templates from feces and primers ITS1-F/ITS2-R, yielding a 347-bp product corresponding to $V$. dahliae. Control reactions include the use of $20 \mathrm{ng}$ of DNA extracted from pure mycelia of $V$. dahliae isolate 999-1 (C+) and no DNA (C-). "L" represents the molecular weight marker (ladder).

Table 2. Inoculation efficiency of manure in eggplant plants

\begin{tabular}{|c|c|c|c|c|}
\hline \multirow[b]{2}{*}{ Disease parameter } & \multirow[b]{2}{*}{ df } & \multirow[b]{2}{*}{$F$ valuesw $^{\text {w }}$} & \multicolumn{2}{|c|}{ Treatment $^{\mathbf{v}}$} \\
\hline & & & Control plants & Manure-treated plants \\
\hline Disease incidence $(\%)^{\mathrm{x}}$ & 4 & $16.000 * * *$ & $0.00 \pm 0.00 \mathrm{a}$ & $58.33 \pm 4.16 b$ \\
\hline Disease severity $(\%)^{\mathrm{y}}$ & 46 & $77.717 * * *$ & $0.00 \pm 0.00 \mathrm{a}$ & $30.65 \pm 7.81 \mathrm{~b}$ \\
\hline Positive $V$. dahliae isolations $(\%)^{\mathrm{z}}$ & 46 & $329.092 * * *$ & $0.00 \pm 0.00 \mathrm{a}$ & $48.33 \pm 9.20 b$ \\
\hline
\end{tabular}

v Eggplant plants ('Black Beauty') at the two-true-leaf stage were transplanted in pots containing soil substrate (Potground; Klasmann) amended with 20\% decomposed manure (Manure-treated plants) or transplanted in $100 \%$ soil substrate (Control plants). Plants were further maintained in a greenhouse at $22 \pm$ $5^{\circ} \mathrm{C}$ with a 12 -h photoperiod for another 112 days.

${ }^{\text {w }}$ Asterisks (***) indicate significance at the $P<0.001$ level, according to the $F$ test.

${ }^{x}$ Mean disease incidence of 24 plants was estimated as the percentage of infected plants, 112 days after transplanting. Arcsin transformation was performed prior to statistical analysis. Within rows, values with different letters differ significantly according to $t$ test $(P \leq 0.001)$.

y Mean disease severity of 24 plants was calculated from the number of leaves that showed wilting as a percentage of the total number of leaves of each plant, 112 days after transplanting. Arcsin transformation was performed prior to statistical analysis. Within rows, values with different letters differ significantly according to the $t$ test $(P \leq 0.001)$.

${ }^{z}$ Positive $V$. dahliae isolations were performed by cutting plants above the soil level and placing 10 wood chips from the stem of each plant, after the removal of the bark, onto acidified potato-dextrose agar. Plates were incubated at $22^{\circ} \mathrm{C}$ in the dark for 14 days. Pathogen isolation ratio was expressed as percentage of positive $V$. dahliae isolation for each plant. Arcsin transformation was performed prior to statistical analysis. Within rows, values with different letters differ significantly according to the $t$ test $(P \leq 0.001)$. 
formed in infected forage that could potentially survive passage through the digestive system of sheep and infest host plants. Pathogenicity tests for infested forage preparation revealed that eggplant was the most susceptible host and all $V$. dahliae isolates were pathogenic on eggplant. Therefore, this host was selected to confirm the infection efficiency of manure by bioassays. Furthermore, data regarding the reaction of four plant hosts to $V$. dahliae isolates confirmed the large genetic variation within species, which is expressed as differences in virulence and pathogenicity to specific hosts. The knowledge of genetic and virulence diversity of $V$. dahliae populations in a specific field would be valuable, especially if the variation in these populations, in practice, is limited enough for allowing the use of hosts that are not affected (15).

Spreading of $V$. dahliae propagules by infested manure has been previously reported by Lopez-Escudero and Blanco-Lopez (19). They assumed that olive plants showed Verticillium wilt symptoms caused by the surviving structures of the fungus in manure. However, pathogenicity tests were not conducted to verify that viable propagules which passed through the digestive tract of animals are still capable of invading new hosts. In the present study, it was directly corroborated that $V$. dahliae propagules (probably microsclerotia) can overcome the digestive process and remain infective in eggplant plants, thus demonstrating the active role of $V$. dahliae after passage through the digestive system of sheep as effective inoculum for eggplant host. Other researchers (11) have likewise revealed the survival and infection efficiency of $V$. albo-atrum, isolated from fecal samples of sheep, in alfalfa. In addition, $V$. albo-atrum has been shown to remain viable in insect feces and able to infect alfalfa plants near the infested feces (10).

DNA extraction from fecal samples and PCR amplification with specific primers for $V$. dahliae detection were employed, in order to determine the excretion of the fungus from the animal body. Replicated PCR assays revealed that one of the four animals (sheep A) harbored and was able to disperse pathogen propagules only the first day after feeding whereas, in two animals (sheep B and C), the fungus was detected for two consecutive days (on days 3 to 4 and 1 to 2 after feeding, respectively). Interestingly, in sheep D, fungal DNA was detected until day 5 post treatment, except on day 4. This 1-day gap in $V$. dahliae detection could be attributed to the physiology of digestion in ruminants, regarding digestion of plantbased food by initially softening it within the animal's first compartment of the stomach, principally through bacterial actions, then regurgitating the semidigested mass back to the mouth and chewing it again (3). Otherwise, the absence of a PCR product in day 4 could be attributed to just an artifact due to various reasons (29). No detection of $V$. dahliae was achieved beyond the fifth day, indicating no further dissemination of the pathogen. In contrast, Huang et al. (11) showed that all the diseased alfalfa tissues passed through the digestive system within 2 days. The longer span persistence of $V$. dahliae in an animal body revealed in the present study, compared with $V$. albo-atrum observed previously (11), could be due to the less-tolerant structures of the latter species (melanized hyphae versus microsclerotia). Another possible explanation is that $V$. dahliae propagules are formed in extremely higher amounts in senescing tissues of artificially inoculated forage compared with those formed in naturally diseased alfalfa plants, which were used as infested diet formerly (11). Even the different detection methods employed in the two studies (PCR here instead of isolation on selective media previously) may play a role for the observed differences. Furthermore, differences in $V$. dahliae persistence inside the bodies of individual sheep might be explained by the unequal quantities of infested forage consumed by each animal.

In view of all the above, the data of the present study suggest the important role of sheep as carriers in $V$. dahliae transmission. The animal may feed on diseased plants, even weeds, and then spread the pathogen within a field or other distant fields, contributing in pathogen dispersion and increasing Verticillium wilt incidence. As has been previously recommended, tests should be performed before manure application to assure that it is pathogen-free (19). Furthermore, grazing should be avoided in harvested or abandoned fields with evidence of Verticillium wilt, because sheep can potentially transmit the pathogen even to distant areas, contributing to the increase of microsclerotia density in soil. The present study suggests that no more than 5 days are required for the passage of $V$. dahliae through the digestive system of sheep; therefore, enclosing the flock in the fold for six or more days after grazing on infested stubble and feeding them with pathogen-free rations could contribute toward the prevention of $V$. dahliae dispersion. It is evident that further study is needed to elucidate more potential vectors for $V$. dahliae and other plant pathogens, especially those that form tolerant structures, capable of surviving the digestive process in the animal gastrointestinal tract. This would be a substantial breakthrough in the effort to control some of the most serious plant diseases.

\section{Literature Cited}

1. Bhat, R. G., Smith, R. F., Koike, S. T., Wu, B. M., and Subbarao, K. V. 2003. Characterization of Verticillium dahliae isolates and wilt epidemics of pepper. Plant Dis. 87:789-797.

2. Bhat, R. G., and Subbarao, K. V. 1999. Host range specificity in Verticillium dahliae. Phytopathology 89:1218-1225.

3. Church, D. C., ed. 1993. The Ruminant Animal Digestive Physiology and Nutrition. Waveland Press, Inc., Prospect Heights, IL.

4. Daayf, F., Nicole, M., and Geiger, J. P. 1995. Differentiation of Verticillium dahliae populations on the basis of vegetative compatibility and pathogenicity on cotton. Eur. J. Plant Pathol. 101:69-79.

5. Dervis, S., Yetisir, H., Yildirim, H., Tok, F. M., Kurt, S., and Karaca, F. 2009. Genetic and pathogenic characterization of Verticillium dahliae isolates from eggplant in Turkey. Phytoparasitica 37:467-476.

6. Gore, M. E. 2009. Vegetative compatibility and pathogenicity of Verticillium dahliae isolates from chrysanthemum in Turkey. Phytoparasitica 37:87-94

7. Horiuchi, S., Hagiwara, H., and Takeuchi, S. 1990. Host specificity of isolates of Verticillium dahliae towards cruciferous and solanaceous plants. Pages 285-298 in: Biological Control of Soil-Borne Plant Pathogens. D. Hornby, ed. CAB International, Wallingford, UK.

8. Horner, C. E. 1954. Pathogenicity of Verticillium isolates to peppermint. Phytopathology 44:239-242.

9. Howard, R. J. 1985. Local and long-distance spread of Verticillium species causing wilt of alfalfa. Can. J. Plant Pathol. 7:199-202.

10. Huang, H. C., and Harper, A. M. 1985. Survival of Verticillium alboatrum from alfalfa in feces of leaf-chewing insects. Phytopathology 75:206-208.

11. Huang, H. C., Hironaka, R., and Howard, R. J. 1986. Survival of Verticillium albo-atrum in alfalfa tissues buried in manure of fed to sheep. Plant Dis. 70:218-221.

12. Huang, H. C., Richards, K. W., and Kokko, E. G. 1986. Role of leafcutter bee in dissemination of Verticillium albo-atrum in alfalfa. Phytopathology 76:75-79.

13. Inderbitzin, P., Bostock, R. M., Davis, R. M., Usami, T., Platt, H. W., and Subbarao, K. V. 2011. Phylogenetics and taxonomy of the fungal vascular wilt pathogen Verticillium, with the descriptions of five new species. PLoS One 6:e28341.

14. Ispahani, S. K., Goud, G. C., Termorshuizen, A. J., Morton, A., and Barbara, D. J. 2008. Host specificity, but not high-temperature tolerance, is associated with recent outbreaks of Verticillium dahliae in chrysanthemum, in the Netherlands. Eur. J. Plant Pathol. 122:437-442.

15. Ligoxigakis, E. K., and Markakis, E. A. 2012. Incidence and pathogenicity of races and isolates of Verticillium dahliae in Crete, southern Greece. Phytoparasitica 40:493-506

16. Ligoxigakis, E. K., and Vakalounakis, D. J. 1994. The incidence and distribution of races of Verticillium dahliae in Crete. Plant Pathol. 43:755-758.

17. Ligoxigakis, E. K., Vakalounakis, D. J., and Thanassoulopoulos, C. C. 2002. Host range of Verticillium dahliae in cultivated species in Crete. Phytoparasitica 30:141-146.

18. Ligoxigakis, E. K., Vakalounakis, D. J., and Thanassoulopoulos, C. C. 2002. Weed hosts of Verticillium dahliae in Crete: Susceptibility, symptomatology and significance. Phytoparasitica 30:511-518.

19. Lopez-Escudero, F. J., and Blanco-Lopez, M. A. 1998. First report of transmission of Verticillium dahliae by infested manure in olive orchards in Andalucía (Southern Spain). Plant Dis. 83:178.

20. Markakis, E. A., Tjamos S. E., Antoniou, P. P., Paplomatas, E. J., and Tjamos, E.C. 2009. Symptom development, pathogen isolation and RealTime QPCR quantification as factors for evaluating the resistance of olive cultivars to Verticillium pathotypes. Eur. J. Plant Pathol. 124:603-611.

21. Neubauer, C., Heitmann, B., and Vogel, C. 2009. Morphology, vegetative compatibility and pathogenicity of Verticillium dahliae isolates from woody ornamentals in Germany. J. Plant Dis. Prot. 116:109-114.

22. Pegg, G. F., and Brady, B. L. 2002. Verticillium Wilts. CABI Publishing, Wallingford, Oxfordshire, UK.

23. Resende, M. L. V., Flood, J., and Cooper, R. M. 1994. Host specialization 
of Verticillium dahliae, with emphasis on isolates from cocoa (Theobroma cacao). Plant Pathol. 43:104-111.

24. Schnathorst, W. C. 1981. Life cycle and epidemiology of Verticillium. Pages 81-111 in: Fungal Wilt Diseases of Plants. M. A. Mace, A. A. Bell, and C. H. Beckman, eds. Academic Press, New York.

25. Soesanto, L., and Termorshuizen, A. J. 2001. Effect of temperature on the formation of microsclerotia of Verticillium dahliae. J. Phytopathol. 149:685-691.

26. Tjamos, E. C. 1981. Virulence of Verticillium dahliae and V. albo-atrum isolates in tomato seedlings in relation to their host of origin and the applied cropping system. Phytopathology 71:98-100.

27. Vallad, G. E., Qin, Q. M., Grube, R., Hayes, R. J., and Subbarao, K. V. 2006. Characterization of race-specific interactions among isolates of Verti cillium dahliae pathogenic on lettuce. Phytopathology 96:1380-1387.

28. Wilhelm, S. 1955. Longevity of the Verticillium wilt fungus in the laboratory and field. Phytopathology 45:180-181.

29. Wilson, I. G. 1997. Inhibition and facilitation of nucleic acid amplification Appl. Environ. Microbiol. 63:3741-3751. 